\title{
Metal Ion-Mediated Nitric Oxide Generation From Polyurethanes via Covalently Linked Copper(II)-Cyclen Moieties
}

\author{
Simona C. Puiu, ${ }^{1}$ Zhengrong Zhou, ${ }^{1,2}$ Cortney C. White, ${ }^{1}$ Laura J. Neubauer, ${ }^{1}$ Zhenfang Zhang, ${ }^{1}$ \\ Laura E. Lange, ${ }^{1}$ Joel A. Mansfield, ${ }^{1}$ Mark E. Meyerhoff, ${ }^{2}$ Melissa M. Reynolds ${ }^{1}$ \\ ${ }^{1}$ MC3, Inc, Ann Arbor, Michigan \\ ${ }^{2}$ Department of Chemistry, University of Michigan, Ann Arbor, Michigan
}

Received 29 September 2008; revised 11 February 2009; accepted 2 March 2009

Published online 13 May 2009 in Wiley InterScience (www.interscience.wiley.com). DOI: 10.1002/jbm.b.31391

\begin{abstract}
Polyurethanes are widely used in the manufacturing of biomedical catheters and other blood-contacting devices; however, thrombus formation still occurs, which renders these catheters ineffective unless systemic anticlotting agents are used. Nitric oxide (NO) is a wellknown inhibitor of platelet activity. In the current study, two commercially available medical polyurethanes (Pellethane ${ }^{\mathrm{TM}}$ and Tecophilic ${ }^{\mathrm{R}}$ ) were derivatized to possess NO-generating $\mathrm{Cu}$ (II)-cyclen moieties pendant to the polymer backbone. A new three-step synthetic approach is used, that is simpler than a recently reported method to prepare $\mathrm{Cu}$ (II)-cyclen-polyurethane materials. Both derivatized polyurethanes were found to produce NO at levels at or above those of endothelial cells. A comparison between the modified commercial polyurethanes (hydrophobic vs. hydrophilic) is presented, including the synthetic scheme, extensive characterization, and coating application. These derivatized polymers may serve as useful coatings to prevent clotting on the surface of catheters and other blood-contacting biomedical devices. (C) 2009 Wiley Periodicals, Inc. J Biomed Mater Res Part B: Appl Biomater 91B: 203-212, 2009
\end{abstract}

Keywords: polyurethane; nitric oxide; copper; hemocompatibility; catheter

\section{INTRODUCTION}

Nitric oxide (NO), generated in vivo via the oxidation of $\mathrm{L}-$ arginine using the enzyme NO synthase (NOS), ${ }^{1}$ is a potent inhibitor of platelet function and smooth muscle cell proliferation. It is released at low levels (ca. $1 \times 10^{-10} \mathrm{~mol}$ $\mathrm{cm}^{-2} \mathrm{~min}^{-1}$ ) from the surface of endothelial cells (EC), which line the walls of all blood vessels. ${ }^{2,3}$ It has been shown previously that materials that can produce $\mathrm{NO}$ at fluxes comparable to the EC greatly reduce thrombosis on the surface of various biomedical devices, thereby improving their hemocompatibility. ${ }^{4-10}$

Exogenous NO donors, such as diazeniumdiolates (NONOates) and synthetic $S$-nitrosothiols (RSNOs), are capable of releasing $\mathrm{NO}$ in the presence of other activators. For example, $N$-diazeniumdiolates that release $\mathrm{NO}$ when exposed to water or to the physiological environments (i.e., blood, body fluid, etc), are one of the most well recognized classes of NO donors and have been used within a variety of polymer matrices to prepare NO-releasing polymeric coatings (see Figure 1-I). ${ }^{11,12}$ In addition, materials that use $S$-nitrosothiols covalently tethered to the surface of fumed

Correspondence to: M. M. Reynolds (e-mail: mreynolds@MC3corp.com) (C) 2009 Wiley Periodicals, Inc. silica that can release NO in the presence of copper ions, ascorbate, or light have been recently reported (see Figure 1 -II). ${ }^{13,14}$

Although the strategy of using NO donors either embedded within or covalently linked to polymers has proven successful in preventing thrombus, using these systems as coatings for long-term implants, such as vascular grafts or hemodialysis catheters, is limited by the finite NO-releasing capacity of such biomaterials. In addition, the labile nature of most NO donors (heat, light, and moisture sensitive) limits their practical manufacturability and, thus, clinical utility.

To overcome these limitations, an alternative approach to prepare NO-producing polymers has recently been explored. S-Nitrosothiols (RSNOs) are endogenous compounds known to be involved in NO storage and transport in blood and are implicated in blood pressure regulation and other physiological processes. ${ }^{15}$ It has been shown that RSNO decomposition can be facilitated by $\mathrm{Cu}$ (II)-complexes $^{16-18}$ and other species (e.g., organoselenium ${ }^{19,20}$ and organotellurium $^{21,22}$ ) to release NO from these endogenous NO carriers (as shown in Figure 1-III). In the case of $\mathrm{Cu}(\mathrm{II})$ and certain complexes of this ion, $S$-nitrosothiols decompose to generate NO through a $\mathrm{Cu}(\mathrm{I})$-mediated process, where $\mathrm{Cu}(\mathrm{I})$ is produced by reduction of $\mathrm{Cu}(\mathrm{II})$ (peptide or protein bound) by $\mathrm{RS}^{-}$, in accordance to the reaction scheme summarized in Scheme $1 .^{23-25}$ 


\section{$\begin{array}{lll}\text { Chemistry } & \text { Polymer coatings } & \text { Blood phase }\end{array}$}

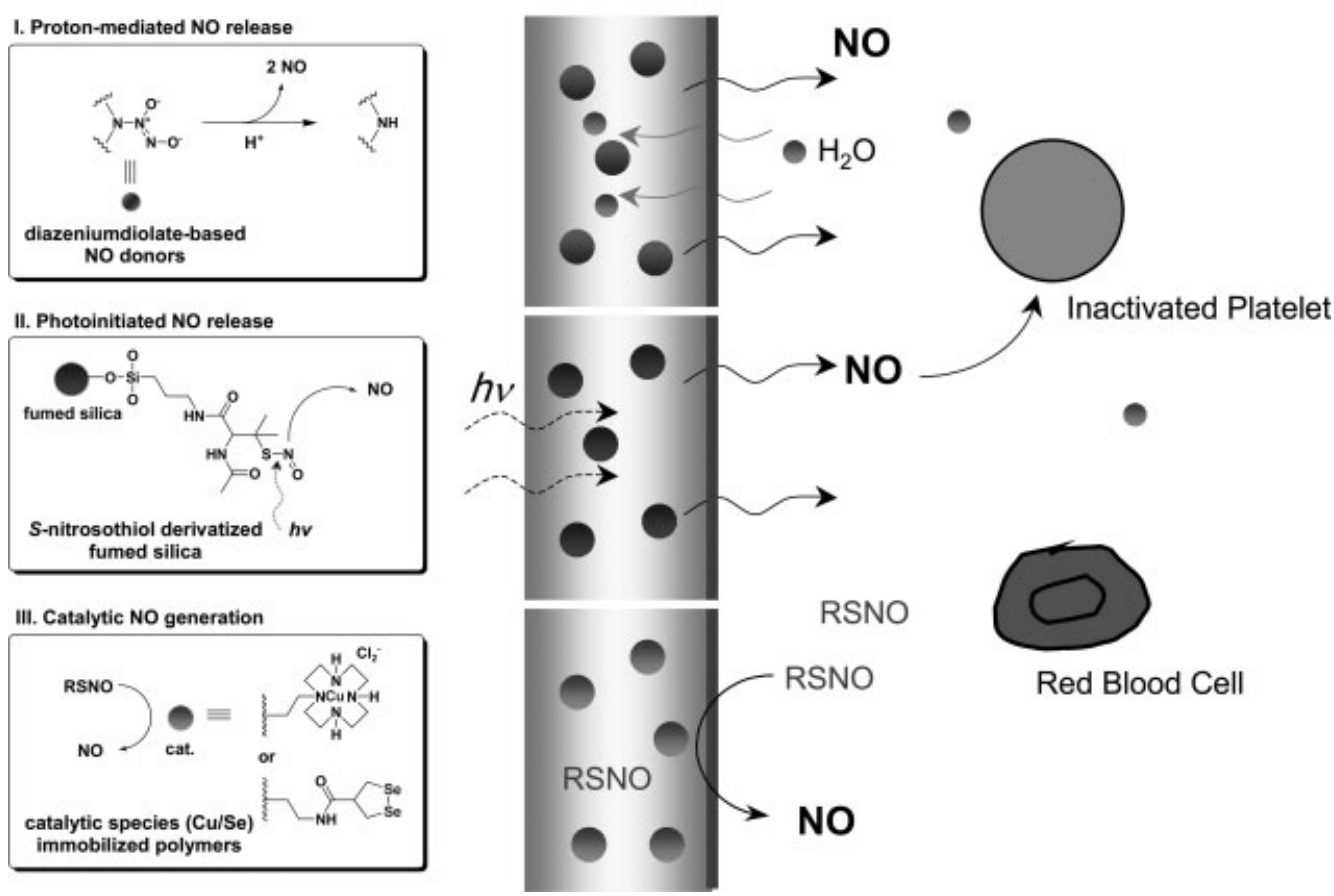

Figure 1. Summary of a variety of NO-releasing/generating strategies examined to devise potentially more blood-compatible polymeric coatings.

Using this chemistry, it has been shown that dispersing a lipophilic $\mathrm{Cu}(\mathrm{II})$-complex into polyurethanes ${ }^{16}$ as well as covalently linking the ligand sites to a polymethacrylate-type hydroge $1^{17}$ yield polymeric materials that produce NO when exposed to physiological levels of RSNOs. In addition, a recent article described a four-step synthetic route to prepare a $\mathrm{Cu}(\mathrm{II})$-cyclen-containing polyurethane. This was accomplished by coupling $\mathrm{Cu}$ (II)-cyclen to the polymer backbone via a diisocyanate linker followed by amination and cyclen addition. This polyurethane has been reported to produce $\mathrm{NO}$ at a flux of $1 \times 10^{-10} \mathrm{~mol}$ $\mathrm{cm}^{-2} \mathrm{~min}^{-1}$ when exposed to $\mu \mathrm{M}$ concentrations of RSNOs. ${ }^{18}$

In this article, we report a new and simpler three-step synthetic method to modify medical grade polyurethanes (e.g., Pellethane ${ }^{\mathrm{TM}}$ and Tecophilic $^{\circledR}$ ) to yield polymers with pendant $\mathrm{Cu}(\mathrm{II})$-ligand sites. The method eliminates the need for the aminated linker and produces polymeric materials that yield $\mathrm{NO}$ at levels exceeding those of $\mathrm{EC}$ when in contact with physiological RSNO concentrations. Furthermore, we demonstrate the universality of this synthetic method using both aliphatic- and aromatic-based hard segmented PUs. A comparison between the two types of deriv-

$$
\begin{aligned}
& \mathrm{Cu}^{\mathrm{I}}+\mathrm{RSNO} \rightarrow \mathrm{Cu}^{\mathrm{II}}+\mathrm{RS}^{-}+\mathrm{NO} \\
& 2 \mathrm{Cu}^{\mathrm{II}}+2 \mathrm{RS}^{-} \rightarrow 2 \mathrm{Cu}^{\mathrm{I}}+\mathrm{RSSR}^{-}
\end{aligned}
$$

Scheme 1. S-nitrosothiol degradation mediated by $\mathrm{Cu}(\mathrm{l})$ ions. atized polyurethanes (hydrophobic vs. hydrophilic) and their potential utility in catheter coatings is discussed.

\section{MATERIALS AND METHODS}

\section{Materials}

Tecophilic ${ }^{\circledR}$ SP-60D-60 polyurethane (TPU) and Carbothane ${ }^{\circledR}$ tubing were obtained from Lubrizol (Wickliffe, $\mathrm{OH}$ ), Pellethane $\mathrm{TM}^{\mathrm{TM}}$ 2363-80AE (Pell) was a product of Dow Chemical (Midland, MI). Hexamethylene diisocyanate (HMDI, Sigma-Aldrich) was either used fresh or distilled at reduced pressure before use, and stored under nitrogen at $4^{\circ} \mathrm{C}$. Cyclen was purchased from Strem Chemicals (Newburyport, MA) and used without further purification. Copper(II) chloride dihydrate and dibutyltin dilaurate (DBTDL) were purchased from Sigma-Aldrich (St. Louis, MO). Trifluoroacetic acid was a product of Fisher Scientific (Pittsburgh, PA). Anhydrous tetrahydrofuran (THF), anhydrous diethyl ether, anhydrous $N, N$-dimethylacetamide (DMAc), anhydrous $N, N$-dimethylformamide (DMF), and sodium bicarbonate were products of EMD (Gibbstown, NJ). Chloroform and diethyl ether were purchased from VWR International (West Chester, PA). THF was purchased from Acros Organics (Morris Plains, NJ). Deuterated solvents (THF- $d_{8}$ and $\mathrm{CDCl}_{3}$ ) were purchased from Cambridge Isotope Laboratories (Andover, MA). 1,4,7-Tris(tert-butyloxycarbonyl)-1,4,7,10-tetraazacyclododecane (Tri-Boc cyclen) was synthesized using a previously reported procedure. ${ }^{17}$ 
RSNOs were freshly prepared by methods reported previously. ${ }^{15,20}$

\section{General Methods}

${ }^{1}$ HNMR spectra of all the intermediates and the final polymers were obtained either on a Varian Inova $400 \mathrm{MHz}$ or on a Varian Mercury $300 \mathrm{MHz}$ spectrometer. FTIR spectra were collected on a Perkin Elmer spectrum BX FTIR system with an ATR accessory (ZnSe crystal). Copper concentrations in water were determined using AquaChek test strips (Hach company, Overland, CO) capable of detecting

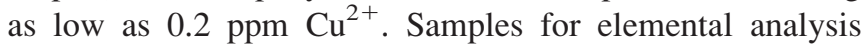
$(\mathrm{C}, \mathrm{H}, \mathrm{N}$, and $\mathrm{Cu}$ ) were sent to Tucson Laboratory (Tucson, AZ). Molecular weight determinations (GPC) were made using a Perkin Elmer Series 200 HPLC system with a series of Waters $10 \mu \mathrm{m}$ particle size, $4.6 \mathrm{~mm}$ diameter Styragel $^{\circledR}$ GPC columns heated to $25.5^{\circ} \mathrm{C}$ with $\mathrm{THF}$ as the mobile phase at $0.5 \mathrm{~mL} / \mathrm{min}$ flow rate. Detection was accomplished using a Hitachi L-2490 refractive index (RI) detector in series after a Perkin Elmer 235C UV-vis Diode Array Detector (PDA) set to $245 \mathrm{~nm}$. Data analysis of the chromatograms was performed using Total Chrom Navigator version 6.3.1 and TurboSEC version 6.3.1.0504. Samples and polystyrene standards (Shodex SM-105) were dissolved in THF (JT Baker) at a concentration of $2 \mathrm{mg} /$ $\mathrm{mL}$ and toluene was added as internal standard. Mechanical strength (tensile) of TPU and TPU-NCON-cyclen/Cu(II) was tested using an Instron tester (Model: 2519-107, Canton, MA) on standard film samples (ASTM D 638) using a 5000-N load cell.

NO measurements were performed by using a Sievers$280^{\mathrm{TM}}$ chemiluminescence-based NO analyzer (CL NOA), model 280i. The instrument was calibrated before each experiment with house nitrogen as the zero gas. The flow rate was set to $200 \mathrm{~mL} / \mathrm{min}$ with a cell pressure of 5.4 Torr and an oxygen pressure of $6.0 \mathrm{psig}$. The measurements were performed by adding the NO-generating polyurethanes into a Chelex-treated PBS buffer with $2.5 \mathrm{mM}$ EDTA. The PBS buffer solution was injected via a pipette to the top of the NOA measurement cell (covered with aluminum foil to prevent light decomposition of the $S$-nitrosothiols), purged and then the GSH and GSNO solution was added. The NO produced from the sample was flushed from the solution into the chemiluminescence chamber via a constant nitrogen purge. The data were recorded using NOA Plot software and processed using Excel.

Cytotoxicity testing was conducted at NAMSA (Northwood, $\mathrm{OH})$.

\section{Synthesis of $\mathrm{Cu}(\mathrm{II})-$ Cyclen-Derivatized Polyurethanes}

Pellethane $^{\mathrm{TM}}$ With Free Pendant Isocyanate Groups (Pell-NCO). A solution of Pellethane ${ }^{\mathrm{TM}}$ (20 g, containing $53.2 \mathrm{mmol}$ urethane groups) in $400 \mathrm{~mL}$ anhydrous DMAc was added dropwise via a syringe pump to an approximately fivefold molar excess of HMDI solution $(42.8 \mathrm{~mL}$,
$266.4 \mathrm{mmol}$ in $50 \mathrm{~mL}$ anhydrous DMAc) under argon at $40^{\circ} \mathrm{C}$ in the presence of a tin catalyst (DBTDL, $0.8 \mathrm{~mL}$ ). The reaction mixture was stirred at $40^{\circ} \mathrm{C}$ for up to 6 days. A small amount of reaction solution was sampled, worked up at a given interval (precipitated in dry diethyl ether) to isolate a purified polymer and measured with IR by examining the increase in the intensity of NCO band at ca. 2270 $\mathrm{cm}^{-1}$ to follow the extent of isocyanate group incorporation. After 6 days of reaction, the solution was poured into and precipitated with a large excess of anhydrous ether (200 $\mathrm{mL}$ reaction solution per $2 \mathrm{~L}$ ether). The precipitate was filtered and further washed via Soxhlet extraction using dry ether over $\mathrm{CaH}_{2}$ under argon for 2 days to completely remove any unreacted HMDI and remaining DBTDL. The resulting product was then dried under vacuum for 1 day and used immediately for the next step or stored in the freezer under argon for future use. However, because of the unstable nature of the isocyanate-containing polymer, longterm storage should be avoided to ensure good quality of the material. IR (neat): $2270 \mathrm{~cm}^{-1}$ (NCO).

Attachment of Tri-Boc Cyclen to the Activated Pellethane $^{\mathrm{TM}}$ (Pell-NCON-cyclen-Boc). For cyclen attachment, $690 \mathrm{mg}$ of Pell-NCO was first dissolved in $16 \mathrm{~mL}$ of anhydrous THF to form a homogeneous solution (note: insoluble gel-type polymer could be observed during the dissolution if the Pell-NCO used was stored for an extended period of time and underwent hydrolysis/crosslinking). To the solution was added $173 \mathrm{mg}$ of tri-Boc cyclen $(0.37 \mathrm{mmol})$, and then the reaction mixture was flushed with argon and stirred at room temperature. After reaction for 2 days, another $173 \mathrm{mg}$ of tri-Boc cyclen $(0.37$ mmol) was added and the reaction was resumed stirring at room temperature. The reaction was monitored at given intervals by sampling and precipitating a small amount of the reaction mixture with ether, and recording the IR spectrum of the product to follow the decrease in the intensity of NCO band at $2270 \mathrm{~cm}^{-1}$. After another 3 days of reaction, no isocyanate band could be observed in the IR spectrum, and the reaction mixture was then precipitated with $300 \mathrm{~mL}$ of ether. A white precipitate was collected and further washed via Soxhlet extraction with ether for 2 days to completely remove any unbound small molecules. The resulting polymer was then dried under vacuum for 1 day to provide $690 \mathrm{mg}$ of Pell-NCON-cyclen-Boc.

Boc-Deprotection of Immobilized Cyclen (Pell-NCONcyclen). To remove the Boc group from the immobilized cyclen, $350 \mathrm{mg}$ of Pell-NCON-cyclen-Boc was first dissolved in $15 \mathrm{~mL}$ of chloroform. To this solution was slowly added $5 \mathrm{~mL}$ of trifluoroacetic acid (TFA) with vigorous stirring. The reaction was stirred at room temperature for ca. $12-24 \mathrm{~h}$, then the reaction mixture was poured into 100 $\mathrm{mL}$ of ether and kept in the refrigerator overnight to allow complete precipitation of the polymer. The deprotected product was first washed using Soxhlet extraction with 
ether, and then washed with a sodium bicarbonate solution, water and ethanol to completely remove the TFA salt from cyclen amines. The resulting white polymer was dried under vacuum to quantitatively yield a light yellow polymer product.

Metallation of Immobilized Cyclen with $\mathrm{Cu}$ (II) Ion (Pell-NCON-cyclen/Cu(II)). The metallation reaction was performed by soaking Pell-NCON-cyclen polymer chunks into a $\mathrm{CuCl}_{2}$ /ethanol solution (approximately $10 \mathrm{mg} / \mathrm{mL}$ ) at $37^{\circ} \mathrm{C}$ for $6 \mathrm{~h}$ (or at room temperature overnight). Upon copper ion loading, the color of the polymer changed instantly from white to green in the ethanol solution. The color subsequently changed to bright blue once the polymer was in contact with water. The metallated polymer was extensively washed with water and ethanol to remove unbound free $\mathrm{Cu}$ (II) ions. Control experiments were also performed by loading PellNCON-cyclen-Boc with $\mathrm{Cu}(\mathrm{II})$ under the same conditions.

Tecophilic $^{\circledR}$ PU. Elemental analysis: $60.07 \%$ C, $9.10 \%$ $\mathrm{H}, 4.40 \% \mathrm{~N}$.

Tecophilic ${ }^{\circledR}$ PU With Free Pendant Isocyanate Groups (TPU-NCO). A solution of $10 \mathrm{~g}$ of TPU (containing 31.4 mmol urethane groups - as calculated from elemental analysis above) in $100 \mathrm{~mL}$ anhydrous DMAc was added dropwise via addition funnel to an excess of HMDI solution (21.4 $\mathrm{mL}$ in $25 \mathrm{~mL}$ DMAc) under nitrogen at $40^{\circ} \mathrm{C}$ in the presence of a tin catalyst (DBTDL, $0.4 \mathrm{~mL}$ ). The same procedure was followed as described earlier for the synthesis of Pell-NCO except for the purification step: instead of Soxhlet extraction, the precipitate was filtered and further washed with anhydrous ether $(2 \times 200 \mathrm{~mL})$ to completely remove the unreacted HMDI and remaining DBTDL. The resulting product was then dried under vacuum for 1 day and used immediately in the next step. IR (neat): 2265 $\mathrm{cm}^{-1}$ (NCO).

Attachment of Tri-Boc Cyclen to Tecophilic ${ }^{\circledR}$ PU (TPU-NCON-cyclen-Boc). For cyclen attachment, $10 \mathrm{~g}$ of TPU-NCO was first dissolved in $200 \mathrm{~mL}$ of anhydrous THF to form a homogeneous solution. To the solution was added $1.5 \mathrm{~g}(3.17 \mathrm{mmol})$ of Tri-Boc cyclen, and the reaction mixture was flushed with nitrogen and stirred at room temperature. The same procedure was followed as described above for the synthesis of Pell-NCON-cyclenBoc, except that the reaction was stopped after 4 days (no isocyanate band could be observed in the IR spectrum), and the reaction mixture precipitated with $1000 \mathrm{~mL}$ of ether. A white precipitate formed, which was filtrated and further washed with ether $(2 \times 200 \mathrm{~mL})$ to completely remove the unbound small molecules. The resulting polymer was dried under vacuum for 1 day to provide $8.4 \mathrm{~g}$ of TPU-NCON-cyclen-Boc.
Boc-deprotection of Immobilized Cyclen (TPU-NCONcyclen). To remove the Boc group from the immobilized cyclen, $7.3 \mathrm{~g}$ of TPU-NCON-cyclen-Boc was first dissolved in $100 \mathrm{~mL}$ chloroform. To the solution, $10 \mathrm{~mL}$ of trifluoroacetic acid (TFA) was slowly added with vigorous stirring. The reaction was kept at room temperature for ca. 12-24 h. The solvent was evaporated to dryness, the polymer redissolved in $50 \mathrm{~mL}$ DMF and the reaction mixture was precipitated into $1000 \mathrm{~mL}$ of saturated sodium bicarbonate solution and stirred for $2 \mathrm{~h}$ to completely remove the TFA salt from cyclen amines. The resulting white polymer was filtrated, washed with water, and air dried, providing $6.9 \mathrm{~g}$ TPU-NCON-cyclen. Elemental analysis: $58.83 \%$ C, $8.43 \%$ $\mathrm{H}, 5.20 \% \mathrm{~N}$.

Metallation of Immobilized Cyclen with $\mathrm{Cu}(\mathrm{II})$ Ion (TPU-NCON-cyclen/Cu(II)). The same procedure was followed as described earlier for the synthesis of Pell-NCONcyclen/Cu(II). Films of TPU-NCON-cyclen were soaked in a $\mathrm{CuCl}_{2}$ /ethanol solution $(10 \mathrm{mg} / \mathrm{mL})$ at room temperature overnight, then washed extensively with water and ethanol to remove unbound free $\mathrm{Cu}$ (II) ions. AquaChek test strips were used for the detection of $\mathrm{Cu}$ (II) in the aqueous washings and to make sure that all nonspecifically bound $\mathrm{Cu}$ (II) has been removed. Elemental analysis: $58.63 \% \mathrm{C}, 8.96 \%$ $\mathrm{H}, 5.05 \% \mathrm{~N}, 0.38 \% \mathrm{Cu}$.

Preparation of polymeric films for NO generation studies. NO-generating polyurethane films were prepared by first dissolving PU-NCON-cyclen/Cu(II) in THF (100 $\mathrm{mg} / 2 \mathrm{~mL})(\mathrm{PU}=$ Pell, TPU). The polymer cocktails were then cast into $2.54-\mathrm{cm}$ diameter Teflon rings with a Teflon base. The membranes were allowed to cure overnight and small circular disks with a diameter of 8-10 mm were cut.

Cytotoxicity study. An in vitro study was conducted at NAMSA to evaluate TPU-NCON-cyclen/Cu(II) for potential cytotoxic effects using the ISO elution method-1X minimum essential medium (MEM) extract. The sample used was a $3 \times 5 \mathrm{~cm}$ stainless steel coupon coated with a thin layer of TPU-NCON-cyclen/Cu(II). In brief, a highdensity polyethylene sample (negative control), a reagent control, and a tin stabilized PVC sample (positive control) were used as controls to compare with the results of TPUNCON-cyclen/Cu(II)-coated sample. The test articles were extracted in MEM supplemented with 5\% serum and $2 \%$ antibiotics at $37^{\circ} \mathrm{C}$. Triplicate monolayers of mouse fibroblast cells (L-929) were dosed with each extract and incubated at $37^{\circ} \mathrm{C}$ in the presence of $5 \% \quad \mathrm{CO}_{2}$ for $48 \mathrm{~h}$. Following incubation, the monolayers were examined microscopically to evaluate cell characteristics and percent lysis, using the USP criteria: 0 (no lysis) $\rightarrow 4$ (greater than $70 \%$ lysis). No cytotocixity or cell lysis was observed in any of the test samples and the material received a grade reactivity score of 0 . 

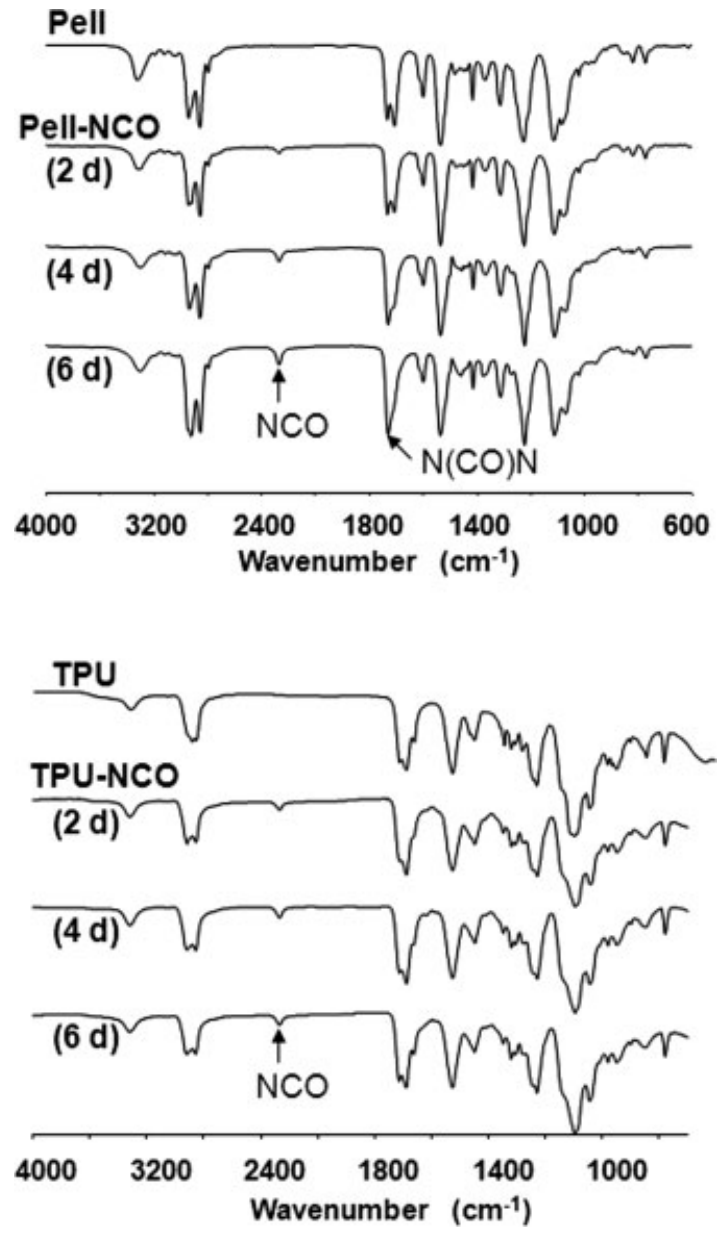

Figure 2. Coupling of free isocyanate group onto Pellethane ${ }^{\mathrm{TM}}$ (Pell) and Tecophilic ${ }^{\mathbb{R}}$ PU (TPU) backbones as monitored using IR spectroscopy; the reactions were performed for 2,4 , and 6 days.

\section{RESULTS}

\section{Synthesis and Characterization of Cyclen/Cu(II)- Immobilized Polymers}

Owing to the common urethane functional group on the backbones of all PUs, similar chemistry can be used to modify different biomedical grade PU materials. Pelletha$\mathrm{ne}^{\mathrm{TM}}$ (Pell) and Tecophilic ${ }^{\circledR}$ PU (TPU) were structurally modified for further cyclen attachment by coupling HMDI directly to the PU backbone through an allophanate reaction between the NCO group and the urethane $\mathrm{NH}$ group according to a previously reported method. ${ }^{26,27} \mathrm{~A}$ tin catalyst, DBTDL, was used to accelerate this reaction. The reactions were performed at a mild temperature $\left(40^{\circ} \mathrm{C}\right)$ with slow addition of PU solution into a great excess of HMDI to reduce the possibility of HMDI cross-linking of separate PU chains. The degree of coupling with time was monitored using IR spectroscopy and following the increase in the intensity of the NCO band at 2270 and $2265 \mathrm{~cm}^{-1}$, respectively, after 2, 4, and 6 days reaction times. Figure 2 shows the yield of the NCO groups coupled to both Pell and TPU depending on the reaction time at $40^{\circ} \mathrm{C}$. It was found that Pell has a higher coupling efficiency than TPU (TPU-NCO is lower in NCO content) given the same reaction time, possibly due to the higher reactivity of aromatic versus aliphatic urethane groups. Six days was an optimal reaction time reported previously for the modification of a similar PU (Biomer) material, and after this time, there was no significant increase in the free NCO content, while the polymer may undergo cross-linking. ${ }^{26}$ The resulting PellNCO prepared here was worked up via Soxhlet extraction using anhydrous ether (in situ dried by $\mathrm{CaH}_{2}$ ) under argon for 2 days to remove any residual HMDI and DBTDL. Diethyl ether was the solvent of choice in this case because it boils at a relatively low temperature $\left(35^{\circ} \mathrm{C}\right)$ while dissolving all the small-molecule impurities, thereby retaining the reactivity of NCO groups during purification. The efficiency of this work-up method was verified by ${ }^{1} \mathrm{HNMR}$. No residual small molecules could be found after 2 days of extraction (see Figure 3). The IR spectra of Pell-NCO before and after such extraction were compared and no decrease in NCO band intensity was observed. New peaks $\left(c, d\right.$, and $e$ ) that appear in the ${ }^{1} \mathrm{HNMR}$ spectrum of Pell$\mathrm{NCO}$ further confirm the successful grafting of $\mathrm{N}(\mathrm{CO}) \mathrm{N}$ $\left(\mathrm{CH}_{2}\right)_{6} \mathrm{NCO}$ moieties onto the Pell backbone. The ratio of aromatic- $H$ peaks at $7 \mathrm{ppm}$ and the adjacent new peaks $e$ (Ar- $\mathrm{H}$ shifting due to grafting of diisocyanate onto adjacent $\mathrm{Ar}-\mathrm{N}$ ) was used to estimate the degree of modification. New peaks $\boldsymbol{d}$, backbone $\mathrm{CH}_{2}$ shifting due to grafting,
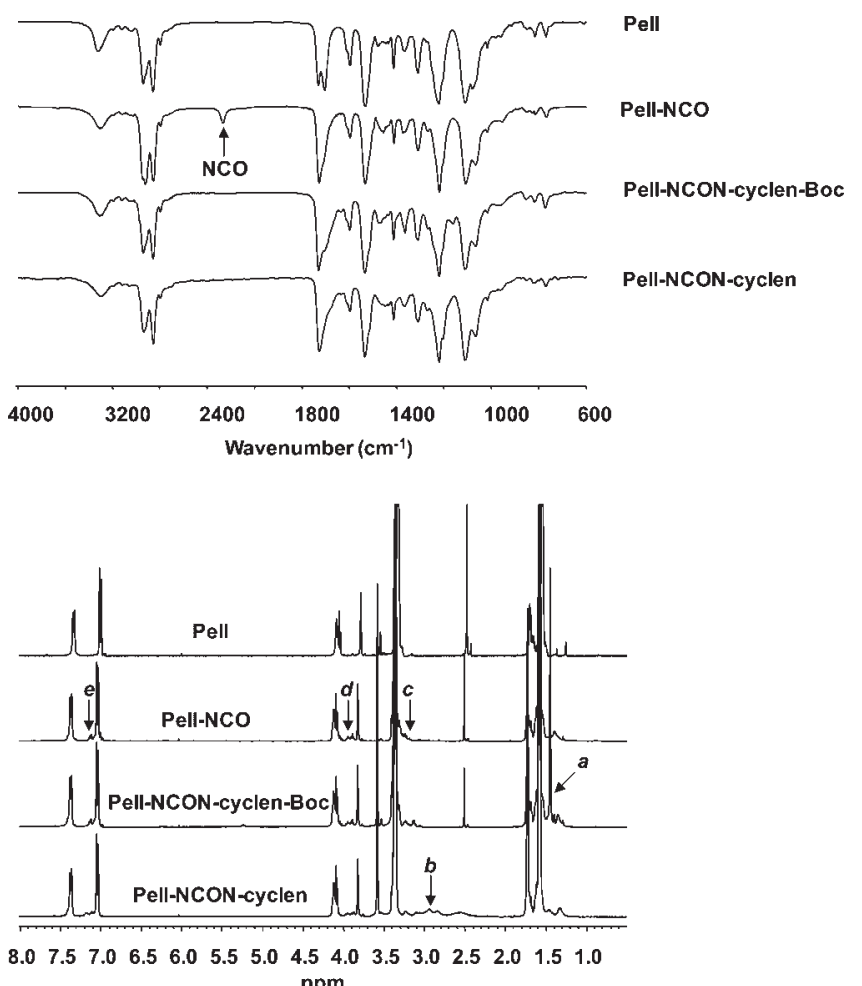

Figure 3. Typical IR and ${ }^{1} \mathrm{HNMR}$ spectra of Pellethane ${ }^{\mathrm{TM}}$ and structurally modified Pellethane ${ }^{\text {TM }}$ polymers $\left({ }^{1} \mathrm{HNMR}\right.$ solvent $=$ THF- $d_{8}$; peak $\boldsymbol{a}$ is from the Boc-group protons, $\boldsymbol{b}$ and $\boldsymbol{c}$ are from the $\mathrm{CH}_{2}$ of the hexamethylene linker, $\boldsymbol{d}$ is from the backbone $\mathrm{CH}_{2}$, and $\boldsymbol{e}$ is from the $\mathrm{Ar}-\mathrm{H}$ adjacent to $\mathrm{Ar}-\mathrm{N}$ ). 


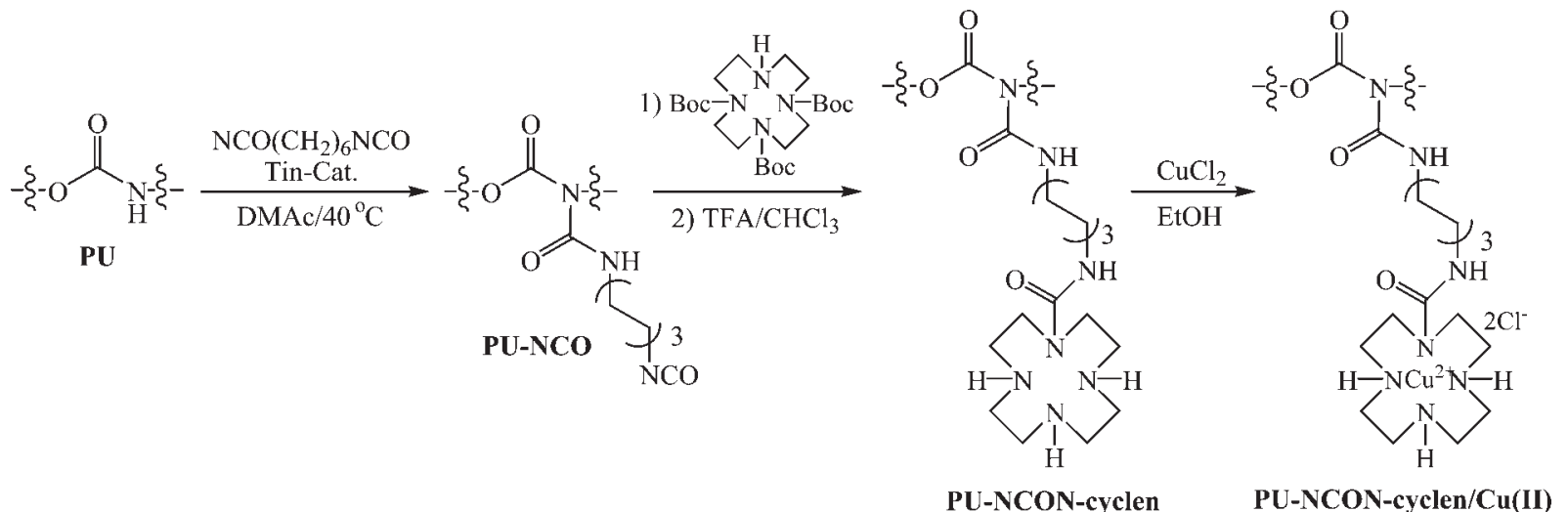

Scheme 2. Synthesis of polyurethanes with covalently linked cyclen/Cu(II) moieties (PU = Pell, TPU).

were used to confirm this value. Based on the ${ }^{1} \mathrm{HNMR}$ integration, the degree of modification was estimated to be ca. $10 \mathrm{~mol} \%$ of the total urethane groups within Pell, which means that the free pendant NCO concentration is ca. $0.266 \mathrm{mmol} / \mathrm{g}$, given that the urethane group concentration within the Pell used herein is ca. $2.66 \mathrm{mmol} / \mathrm{g} .{ }^{28}$

In case of TPU, Soxhlet extraction was deemed unnecessary due to the high diffusivity of the polymer, and simple precipitation from THF/ether and washing with ether was found adequate to remove the excess of any residual small molecules (HMDI and DBTDL). Because of the very small changes in the NMR spectra, due to a low level of NCO incorporation, ${ }^{1} \mathrm{HNMR}$ could not be used to assess the degree of modification. The urethane group concentration in TPU can be estimated from elemental analysis, given that the urethanes are the only source of nitrogen. Results indicated that the material possessed $4.40 \% \mathrm{~N}$, which means that $100 \mathrm{~g}$ TPU contain ca. 0.314 mol $\mathrm{NHC}(\mathrm{O}) \mathrm{O}$ groups or $3.14 \mathrm{mmol} / \mathrm{g}$. This value is comparable to the concentration of urethane groups reported for a related Tecophilic ${ }^{\circledR}$ polyurethane, SP-93A-100 (ca. $\left.4 \mathrm{mmol} / \mathrm{g}\right) .{ }^{18}$

Both PU-NCO materials were further reacted with tri-Boc cyclen ${ }^{17}$ to form PU-NCON-cyclen-Boc (see Scheme 2). Excess amount of tri-Boc cyclen was used to ensure completeness of reaction. The reactions were performed at room temperature in THF and monitored by IR until no NCO band was observed, indicating the completion of the reaction. The characteristic Boc group signal appeared in the ${ }^{1} \mathrm{HNMR}$ spectra (peak $\boldsymbol{a}$ at ca. $1.4-1.5 \mathrm{ppm}$, see Figures 3 and 4). NMR integration showed nearly quantitative conversion of Pell-NCO to Pell-NCON-cyclen-Boc, meaning that ca. 0.266 $\mathrm{mmol}$ cyclen/g were attached.

The deprotection reaction was performed in $\mathrm{CHCl}_{3} / \mathrm{TFA}$, and was also examined using ${ }^{1}$ HNMR spectroscopy. After TFA deprotection, the ${ }^{1}$ HNMR peak associated with the Boc group protons disappeared, indicating the complete removal of the Boc groups (see Figures 3 and 4). In addition, in case of Pell, due to the loss of such an electron-withdrawing group, the proton signals $\boldsymbol{b}$ associated with the $\mathrm{NCH}_{2} \mathrm{CH}_{2} \mathrm{~N}$ structures of the cyclen shifted upfield from a cluster of overlapped peaks (3-4 ppm) to the region of 2.4-3.2 ppm. Except for the disappearance of the Boc group peak, almost no change in the NMR spectrum was observed in case of derivatized TPU.

Identifying the diisocyanate or cyclen groups within the modified TPU-NCON-cyclen polymer using NMR or IR was more difficult due to lower incorporation. An alternative way to determine the degree of cyclen incorporation onto the TPU backbone is based on the elemental analysis. The TPU starting material contains $4.40 \% \mathrm{~N}$ (which corresponds to $0.314 \mathrm{~mol} \mathrm{~N}$ or $0.314 \mathrm{~mol}$ urethane $\mathrm{NHC}(\mathrm{O}) \mathrm{O}$ groups per $100 \mathrm{~g}$ polymer), whereas after the diisocyanate
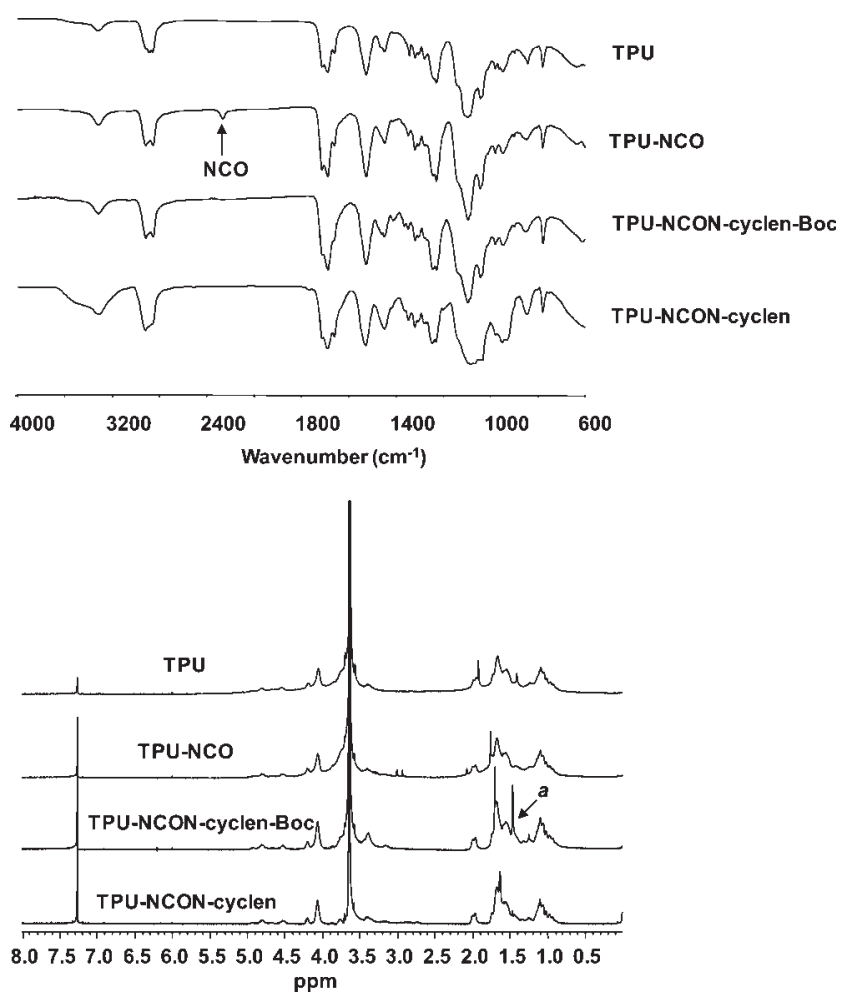

Figure 4. Typical IR and ${ }^{1} \mathrm{HNMR}$ spectra of TPU and structurally modified TPU ( ${ }^{1} \mathrm{HNMR}$ solvent $=\mathrm{CDCl}_{3}$; peak $\boldsymbol{a}$ is from the Bocgroup protons). 


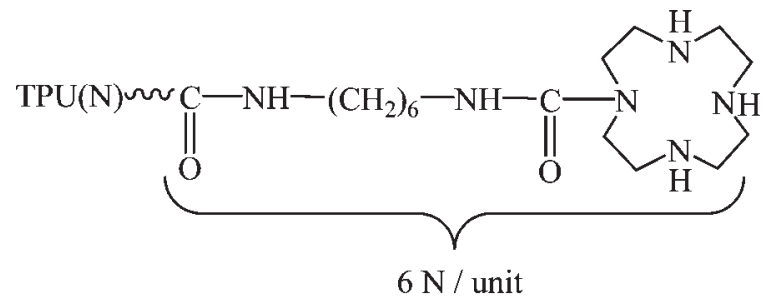

$14.01(0.314-x)+14.01(7 x)=5.20$

$\mathrm{x}=$ mol urethane $\mathrm{NC}(\mathrm{O}) \mathrm{O}$ reacted or mol

cyclen attached (per $100 \mathrm{~g}$ polymer)

$0.314-\mathrm{x}=$ mol urethane $\mathrm{NC}(\mathrm{O}) \mathrm{O}$ unreacted

Scheme 3. Calculation of \% cyclen incorporation in derivatized polyurethane.

and cyclen incorporation, the nitrogen content increases to $5.20 \%$ in TPU-NCON-cyclen. Taking into account that each attached unit contains 6 moles $\mathrm{N}$, the number of attached cyclen units can be calculated (Scheme 3 ). It was found that $x=0.0095 \mathrm{~mol}$ cyclen $/ 100 \mathrm{~g}$ TPU $(0.095$ $\mathrm{mmol} / \mathrm{g}$ ) were linked to the TPU chain.

The cyclen-containing polyurethanes were metallated using copper (II) chloride. Both metallated polyurethanes were characterized using NMR, IR, and UV-vis spectroscopy. For both Pell-NCON-cyclen/Cu(II) and TPU-NCONcyclen/Cu(II), the ${ }^{1} \mathrm{HNMR}$ and IR spectra were not significantly different than those of the cyclen-containing polymers. In addition, Figure 5 shows the UV-vis spectra of PU-NCON-cyclen before and after $\mathrm{Cu}$ (II) incorporation. Again, characteristic absorbance at $680-690 \mathrm{~nm}$ of the $\mathrm{Cu}$ (II)-cyclen complex indicates the formation of PU$\mathrm{NCON}-$ cyclen/Cu(II). To test if $\mathrm{Cu}(\mathrm{II})$ remains immobilized in the presence of aqueous glutathione solution, a 100-mg film of TPU-NCON-cyclen/Cu(II) was soaked in $10 \mathrm{~mL}$ GSH $(50 \mu \mathrm{M})$ for $2 \mathrm{~h}$, and the UV-vis was measured before and after (data not shown). A ca. 9\% decrease in absorbance was observed, probably due to a loss of $\mathrm{Cu}$ (II) but this concentration greatly exceeds the estimated concentration of nitrosothiols in blood (nm to $\mu \mathrm{M}$ range) and, thus, demonstrates strong retention of copper within the ligand. ${ }^{29}$

\section{Molecular Weight Measurements and Mechanical Properties}

Because hydrophilic coatings are preferred by the catheter industry due to easier insertion, we decided to further characterize derivatized TPU for properties specifically related to potential coating processes.

To study structural transformations, such as changes in the molecular weight distribution and/or polydispersity during the reaction sequence, the TPU starting material and the cyclen-derivatized product (nonmetallated) were characterized by gel permeation chromatography (GPC). The GPC was calibrated with polystyrene standards of known average molecular weights. The GPC results (Table I) show that the derivatization reaction is accompanied by a decrease in the molecular weight (both number-average molecular weight $M_{\mathrm{n}}$ and weight-average molecular weight $M_{\mathrm{w}}$ ) and a small increase in the molecular weight distribution (polydispersity index, PDI). The decrease in molecular weight and increase in PDI index may be due to the hydrolysis of some linkages on the polymer backbone during the Boc-deprotection step using TFA.

The stress-strain curves of control (TPU) and final product (TPU-NCON-cyclen/Cu(II)) were determined according to a standard method. ${ }^{30}$ The ultimate tensile strength of the product, which is $10.1 \pm 2.2 \mathrm{MPa}$ (mean \pm standard deviation, $\mathrm{n}=3)$ is higher than that of the control $(8.6 \pm 1.6$ $\mathrm{MPa}(\mathrm{n}=3)$ ), whereas the elasticity (percent strain to failure) of TPU-NCON-cyclen/Cu(II) of $233 \pm 25 \%(\mathrm{n}=3)$ is lower than that of the control $(314 \pm 273 \%,(n=3))$. Values are expressed as the mean \pm standard deviation. The tensile properties of the TPU-NCON-cyclen/Cu(II) material are sufficient for a wide range of medical device applications when strain is under $200 \%$, such as catheters, guidewires, and stents. We also coated mock catheters (Carbothane $^{\circledR}$ tubing, same material and diameter as used in commercial catheters), to assess the adhesion of this material and as a feasibility study toward a clinically usable catheter. Good adhesion to Carbothane ${ }^{\circledR}$ substrate was achieved by simply dip coating the TPU-NCON-cyclen/ $\mathrm{Cu}$ (II) material, as evidenced by no observed peeling after a standard scratch test.
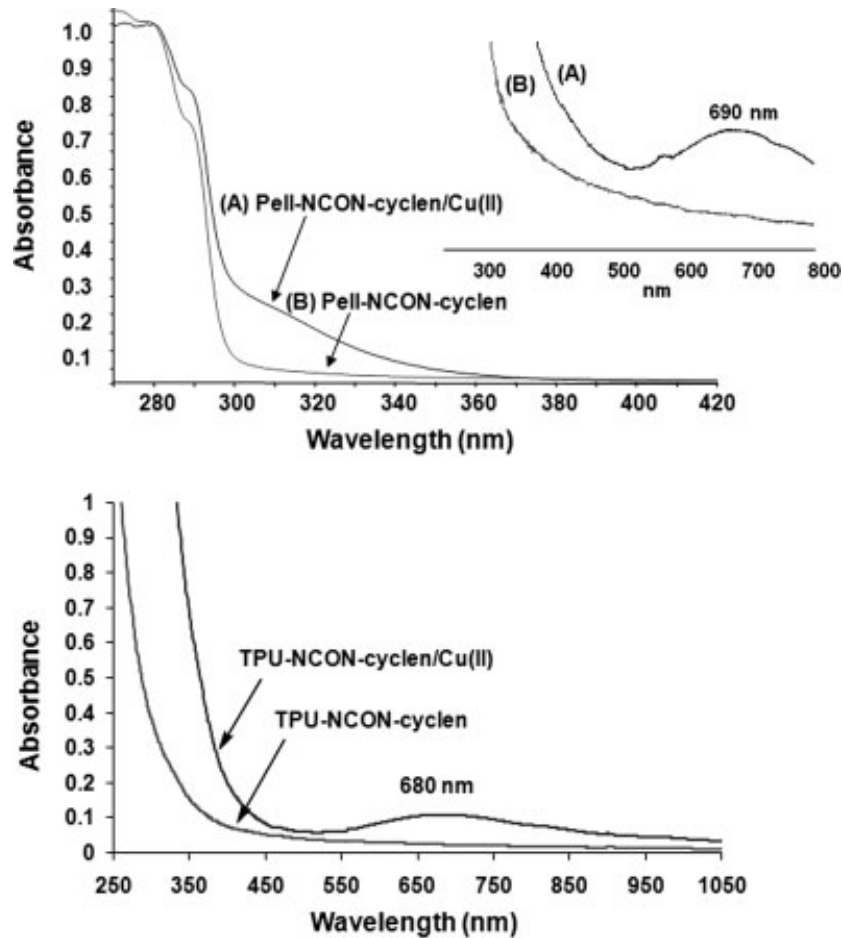

Figure 5. UV-vis spectra of (a) Pell-NCON-cyclen and Pell-NCONcyclen/Cu(II) and (b) TPU-NCON-cyclen and TPU-NCON-cyclen/ $\mathrm{Cu}(\mathrm{II})$ as measured in THF. 
TABLE I. Molecular Weights and Polydispersity Before and After Derivatization of TPU

\begin{tabular}{lccc}
\hline & TPU & TPU-NCON-cyclen-Boc & TPU-NCON-cyclen \\
\hline Peak retention time (PMwt) & $14.16 \min (43,400)$ & $14.7 \min (28,600)$ & 14.9 min $(23,000)$ \\
$M_{\mathrm{w}}$ & 178,000 & 63,300 & 52,700 \\
$M_{\mathrm{n}}$ & 13,800 & 9,100 & 3,370 \\
$M_{\mathrm{w}} / M_{\mathrm{n}}(\mathrm{PDI})$ & 12.9 & 7.0 & 15.6 \\
\hline
\end{tabular}

\section{NO Production}

Polyurethane films were tested for their ability to produce $\mathrm{NO}$ in the presence of $S$-nitrosoglutathione/glutathione (GSNO/GSH) $(50 \mu \mathrm{M})$ via chemiluminescence measurements (see Figure 6). Pell-NCON-cyclen/Cu(II) was found to produce NO at a level of 1.5-2.0 $\times 10^{-10} \mathrm{~mol} \mathrm{~cm} \mathrm{~cm}^{-2}$ $\min ^{-1}$, whereas TPU-NCON-cyclen/Cu(II) gave a much higher surface flux of $44.0 \pm 1.0 \times 10^{-10} \mathrm{~mol} \mathrm{~cm}^{-2} \mathrm{~min}^{-1}$ (mean \pm standard deviation, $\mathrm{n}=3$ ) for the same concentration of GSNO/GSH. As previously stated, given the preferred use of hydrophilic PUs for catheter coatings, additional NO production testing was performed for TPUNCON-cyclen/Cu(II). This material was evaluated within physiological levels of GSNO/GSH (concentrations of 4.85 $\mu \mathrm{M}$ GSNO and $2.47 \mu \mathrm{M}$ GSH) and was still found capable of generating high fluxes of NO $\left(37.7 \pm 3.5 \times 10^{-10} \mathrm{~mol}\right.$ $\mathrm{cm}^{-2} \min ^{-1}, \mathrm{n}=3$ ). Polymer samples that did not contain copper were also evaluated for their ability to produce NO. In all cases, no NO generation was observed from polymers that did not contain $\mathrm{Cu}$ (II). This data support the fact that immobilized $\mathrm{Cu}$ (II) ions are responsible for the NO generation observed with these polymeric materials. Figure 6 illustrates NO generation from Pell-NCON-cyclen/Cu(II) and TPU-NCON-cyclen/Cu(II) as compared with EC.

\section{Cytotoxicity Evaluation}

Cytotoxicity testing is usually the first screening tool for biocompatibility required by the FDA for approval of a biomedical device. To evaluate the biocompatibility of TPU-NCON-cyclen/Cu(II), a cytotoxicity testing was performed on this material using a standard in vitro mammalian cell culture test to determine whether leachables extracted from the material would cause cell lysis of mouse L-929 fibroblast cells. Under the conditions of this study, the test extract showed no evidence of causing cell lysis or toxicity and the TPU-NCON-cyclen/Cu(II) coating received a score of 0 , indicating that the coating is biocompatible.

\section{DISCUSSION}

Polyurethanes are segmented block copolymers composed of hard (aromatic or aliphatic isocyanates plus a chain extender) and soft (polyether or polyester) segments. ${ }^{32}$ Pellethane $\mathrm{e}^{\mathrm{TM}}$ is a high-strength, aromatic thermoplastic polyether urethane. Tecophilic ${ }^{\circledR}$ thermoplastic polyurethanes (TPUs) are aliphatic, polyether-based polyurethanes, which take up large amounts of water (up to $150 \%$ of the weight of the dry resin). In this study, both Pellethane and Tecophilic polyurethanes containing NO-generating moieties were successfully synthesized by incorporating diisocyanate-cyclen pendant structures into the polymer backbone and then performing metallation with $\mathrm{CuCl}_{2}$.

In case of Pell, NMR can be successfully used to confirm the grafting of $\mathrm{C}(\mathrm{O}) \mathrm{NH}\left(\mathrm{CH}_{2}\right)_{6} \mathrm{NCO}$ groups and cyclen onto the Pell backbone and to estimate the degree of modification (ca. $10 \%$ of the total urethane group or 0.266 mmol cyclen/g polymer). For derivatized TPU, cyclen incorporation was calculated from elemental analysis to be ca. $0.095 \mathrm{mmol} / \mathrm{g}$, which is in accord with the higher isocyanate-coupling efficiency observed for Pell compared with TPU. This is likely due to the different reactivity of the two types of urethane groups: aromatic $\mathrm{Ar}-\mathrm{NH}(\mathrm{CO}) \mathrm{O}$ in Pell are more reactive compared with the aliphatic cyclohexane-NH(CO)O in TPU, due to the electron-withdrawing capability of aryl groups.

Based on the UV-vis spectra, the only source of $\mathrm{Cu}$ (II) in the polymer was the one bound to cyclen, as evidenced by the peaks at $680-690 \mathrm{~nm}$ and within the range previously reported for similar $\mathrm{Cu}(\mathrm{II})-$ cyclen complexes. ${ }^{33}$

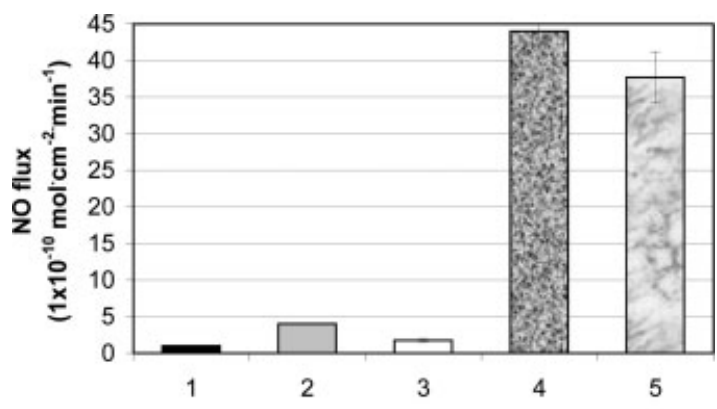

(1) EC

(2) Activated EC

(3) Pell-NCON-cyclen/Cu(II) (a)

(4) TPU-NCON-cyclen/Cu(II) (a)

(5) TPU-NCON-cyclen/Cu(II) (b)

Figure 6. NO generation study for various polymers examined via NOA (at $26^{\circ} \mathrm{C}$ in PBS (treated with Chelex Resin) containing: (a) 2.5 $\mu \mathrm{M}$ EDTA, $50 \mu \mathrm{M} \mathrm{GSH}$, and $50 \mu \mathrm{M}$ GSNO; (b) $2.5 \mu \mathrm{M}$ EDTA, 2.47 $\mu \mathrm{M}$ GSH, and $4.85 \mu \mathrm{M}$ GSNO and comparison with endothelial cells (stimulated and nonstimulated ${ }^{3,31}$ ). 
Both PU-NCON-cyclen/Cu(II) polymers generate $\mathrm{NO}$ at levels higher than healthy EC (per surface units), in the presence of $\mu \mathrm{M}$ concentrations of GSNO/GSH and at physiological $\mathrm{pH}$ (Figure 6). Modified TPU produces a very high flux of NO $\left(44.0 \pm 1.0 \times 10^{-10} \mathrm{~mol} \mathrm{~cm}^{-2} \mathrm{~min}^{-1}\right)$ comparing to modified Pell $\left(1.5-2.0 \times 10^{-10} \mathrm{~mol} \mathrm{~cm}^{-2}\right.$ $\left.\min ^{-1}\right)$. Although the results above seem to indicate that about twice as many cyclen groups are incorporated into the Pell versus TPU backbone, the higher NO generation from TPU-NCON-cyclen/Cu(II) is most likely due to the hydrophilicity of this polymer, and therefore better diffusion/partitioning of RSNO and RSH species into the polymeric layer containing the $\mathrm{Cu}$ (II) sites. Indeed, this finding indicates that the NO generation occurs not only on the polymer surface but also within the bulk of the polymer; both catalyst concentration and polymer hydrophobicity should be considered and balanced during the application of this technology to fabricate coatings that require various levels of NO flux.

Current trends in commercial coatings tend toward hydrophilic surfaces to increase the lubricity of the coat for easy delivery. ${ }^{34}$ Because of its hydrophilicity and higher NO generation, we decided to focus on the TPUNCON-cyclen/ $\mathrm{Cu}$ (II) and to characterize this material further. The GPC results support the fact that no significant cross-linking occurred during the polymer modification, especially when the diisocyanate linker was initially reacted with the polymer. This was also confirmed by solubility test, during which all materials remained relatively soluble in THF. The decrease in the average molecular weight of TPU is probably due to some degradation of the polymer during the three-step modification sequence. However, the decrease in the $M_{\mathrm{w}}$ of modified TPU did not weaken its mechanical properties. Indeed, good tensile strength and elasticity of TPU-NCON-cyclen/Cu(II) were observed when compared with TPU. The higher tensile strength could be due to decrease in the polarity of the hard segment and/or reinforcement/binder effects by adding cyclen/Cu(II). The resulting polymer has mechanical properties and processability close to those of the starting material and may be useful for a variety of coating applications. As an initial assessment, a mock catheter made of Carbothane ${ }^{\circledR}$ was coated with TPU-NCON-cyclen/Cu(II). The coating was even/smooth and had good adherence to Carbothane ${ }^{\mathbb{R}}$ substrate, both dry and hydrated. Because of such properties, combined with its very good NO generation and nontoxic properties, TPU-NCON-cyclen/Cu(II) is a promising candidate and will be used for future preclinical evaluation.

\section{CONCLUSIONS}

A new approach was described to covalently attach cyclen/ $\mathrm{Cu}(\mathrm{II})$ moieties onto structurally modified Pellethane ${ }^{\mathrm{TM}}$ and Tecophilic ${ }^{\mathbb{R}}$ polyurethane backbones, which led to the design of new polyurethane-based materials that produce
NO in the presence of RSNOs. The synthetic method described above is feasible for both aliphatic and aromatic polyurethanes, although there is still room for method improvement and optimization. Two new PU-NCONcyclen/Cu(II) (PU = Pell, TPU) were synthesized and fully characterized. Both polymers possess good processability for coating and casting, and films made of these polymers were capable of generating considerable amounts of NO (comparable to or even greater than EC) from $\mu \mathrm{M}$ levels of GSNO in the presence of GSH. As expected, the percentage of $\mathrm{NCO}$ (and therefore cyclen/Cu(II) sites) incorporation is lower for TPU due to lower reactivity, yet the NO generation is higher due to higher water uptake (hydrophilicity), which allows for much better diffusion of the RSNO species to the active $\mathrm{Cu}$ (II) sites for NO production. Such NO generating polyurethane materials may potentially be used in a wide variety of long-term biomedical applications. In fact, TPU-NCON-cyclen/Cu(II) is our candidate of choice for future in vivo animal studies as a coating material for catheters, vascular grafts and other blood-contacting devices.

Dr. Meyerhoff gratefully acknowledges NIH (grants EB000783 and EB004527) for support of efforts to develop NO generating polymeric coatings.

\section{REFERENCES}

1. Marletta MA. Nitric oxide synthase structure and mechanism. J Biol Chem 1993;268:12231-12234.

2. Ignarro LJ, Buga GM, Wood KS, Byrns RE, Chaudhuri G. Endothelium-derived relaxing factor produced and released from artery and vein is nitric oxide. Proc Natl Acad Sci USA 1987;84:9265-9269.

3. Vaughn MW, Kuo L, Liao JC. Estimation of nitric oxide production and reaction rates in tissue by use of a mathematical model. Am J Physiol Heart Circ Physiol 1998;274:21632176.

4. Peppas NA, Langer R. New challenges in biomaterials. Science 1994;263:1715.

5. Wise DL, Trantolo DJ, Lewandrowski KU, Gresser JD, Cattaneo MV, Yaszemski MJ. Biomaterials Engineering and Devices: Human Applications. Vol. 2: Orthopedic, Dental, and Bone Graft Applications. Totowa, NJ: Humana Press; 2000.

6. Annich GM, Meinhardt JP, Mowery KA, Ashton BA, Merz SI, Hirschl RB, Meyerhoff ME, Bartlett RH. Reduced platelet activation and thrombosis in extracorporeal circuits coated with nitric oxide release polymers. Crit Care Med 2000;28: 915-920.

7. Schoenfisch MH, Mowery KA, Rader MV, Baliga N, Wahr JA, Meyerhoff ME. Improving the thromboresistivity of chemical sensors via nitric oxide release: Fabrication and in vivo evaluation of NO-releasing oxygen-sensing catheters. Anal Chem 2000;72:1119-1126.

8. Mowery KA, Schoenfisch MH, Saavedra JE, Keefer LK, Meyerhoff ME. Preparation and characterization of hydrophobic polymeric films that are thromboresistant via nitric oxide release. Biomaterials 2000;21:9-21.

9. Zhang H, Annich GM, Miskulin J, Osterholzer K, Merz SI, Bartlett RH, Meyerhoff ME. Nitric oxide releasing silicone rubbers with improved blood compatibility: Preparation, char- 
acterization, and in vivo evaluation. Biomaterials 2002;23: 1485-1494.

10. Bamford CH, Middleton IP, al-Lamee KG, Paprotny J. Modification of biomaterials to improve blood compatibility. Int J Artif Organs 1992;15:71-8.

11. Frost MC, Reynolds MM, Meyerhoff ME. Polymers incorporating nitric oxide releasing/generating substances for improved biocompatibility of blood-contacting medical devices. Biomaterials 2005;26:1685-1693.

12. Reynolds MM, Frost MC, Meyerhoff ME. Nitric oxide-releasing hydrophobic polymers: Preparation, characterization, and potential biomedical applications. Free Rad Biol Med 2004; 37:926-936.

13. Frost MC, Meyerhoff ME. Controlled photoinitiated release of nitric oxide from polymer films containing $S$-nitroso- $N$-acetylDL-penicillamine derivatized fumed silica filler. J Am Chem Soc 2004;126:1348-1349.

14. Frost MC, Meyerhoff ME. Synthesis, characterization, and controlled nitric oxide release from $S$-nitrosothiol-derivatized fumed silica polymer filler particles. J Biomed Mater Res A 2005;72:409-419.

15. Stamler JS, Simon DI, Osborne JA, Mullins ME, Jaraki O, Michel T, Singel DJ, Loscalzo J. S-nitrosylation of proteins with nitric oxide: Synthesis and characterization of biologically active compounds. Proc Natl Acad Sci 1992;89:444448.

16. Oh BK, Meyerhoff ME. Spontaneous catalytic generation of nitric oxide from $S$-nitrosothiols at the surface of polymeric films doped with lipophilic copper(II) complex. J Am Chem Soc 2003; 125:9552-9553.

17. Hwang S, Cha W, Meyerhoff ME. Polymethacrylates with a covalently linked $\mathrm{Cu}^{\mathrm{II}}$-cyclen complex for the in situ generation of nitric oxide from nitrosothiols in blood. Angew Chem Int Ed Engl 2006;45:2745-2748.

18. Hwang S, Meyerhoff ME. Polyurethane with tethered copper (II)-cyclen complex: Preparation, characterization and catalytic generation of nitric oxide from $S$-nitrosothiols. Biomaterials 2008;29:2443-2452.

19. Cha W, Meyerhoff ME. S-nitrosothiol detection via amperometric nitric oxide sensor with surface modified hydrogel layer containing immobilized organoselenium catalyst. Langmuir 2006;22:10830-10836.
20. Cha W, Meyerhoff ME. Catalytic generation of nitric oxide from $S$-nitrosothiols using immobilized organoselenium species. Biomaterials 2007;28:19-27.

21. Hwang S, Meyerhoff ME. Organoditelluride-mediated catalytic S-nitrosothiol decomposition. J Mater Chem 2007;17: 1462-1465.

22. Hwang S, Meyerhoff ME. Organoditelluride-tethered polymers that spontaneously generate nitric oxide when in contact with fresh blood. J Mater Chem 2008;18:1784-1791.

23. Askew SC, Barnett DJ, McAninly J, Williams DHL. Catalysis by $\mathrm{Cu}^{2+}$ of nitric oxide release from $S$-nitrosothiols (RSNO). J Chem Soc Perkin Trans 1995;2:741-745.

24. Dicks AP, Williams DHL. Generation of nitric oxide from $S$-nitrosothiols using protein-bound $\mathrm{Cu}^{2+}$ sources. Chem Biol 1996;8:655-659.

25. Dicks AP, Beloso PH, Williams D. Decomposition of $S$-nitrosothiols: The effects of added thiols. J Chem Soc Perkin Trans 1997;2:1429-1434.

26. Park KD, Piao A, Jacobs H, Okano T, Kim SW. Synthesis and characterization of SPUU-PEO-heparin graft copolymers. J Polym Sci Polym Chem 1991;29:1725-1737.

27. Zhou Z, Meyerhoff ME. Preparation and characterization of polymeric coatings with combined nitric oxide release and immobilized active heparin. Biomaterials 2005;26:6506-6517.

28. Han DK, Park KD, Kim YH. Sulfonated poly(ethylene oxide)-grafted polyurethane copolymer for biomedical applications. J Biomat Sci Polym Ed 1998;9:163-174.

29. Giustarini D, Milzani A, Colombo R, Dalle-Donne I, Rossi R. Nitric oxide and $S$-nitrosothiols in human blood. Clin Chim Acta 2003;330:85-98.

30. Standard test methods for tensile properties of plastics.Annual Book of ASTM Standards 1999;8:D638-699.

31. Vaughn MW, Kuo L, Liao JC. Effective diffusion distance of nitric oxide in the microcirculation. Am J Physiol Heart Circ Physiol 1998;274:1705-1714.

32. Lamba NMK, Woodhouse KA, Cooper SL. Polyurethanes in Biomedical Applications. Boca Raton, FL: CRC Press; 1998.

33. Styka MC, Smierciak RC, Blinn EL, DeSimone RE, Passariello JV. Copper (II) complexes containing a 12-membered macrocyclic ligand. Inorg Chem 1978;17:82-86.

34. Ikada Y, Uyama Y. Lubricating Polymer Surfaces. Boca Raton, FL: CRC Press; 1993. 